\title{
Association Between Selected Socio Demographic Variables and Musculoskeletal Symptoms Experienced By Dentists in a Southern Karnataka District
}

\author{
Shaik $A B,{ }^{1}$ Sripathi Rao $B H,{ }^{2}$ Husain $A,{ }^{3} D^{\prime}$ Sa $\mathrm{JL}^{4}$
}

\author{
${ }^{1}$ Yenepoya Physiotherapy College \\ 2Department of Oral \& Maxillofacial Surgery, \\ Yenepoya Dental College \\ ${ }^{3}$ Department of Orthodontics, Yenepoya Dental \\ College \\ ${ }^{4}$ Faculty of Nursing
}

Yenepoya University, Deralakatte, Mangalore, Karnataka

\section{Corresponding Author}

B. H. Sripathi Rao

Yenepoya Dental College

Yenepoya University, Deralakatte, Mangalore, Karnataka

Email: drbhsrao@hotmail.com

\section{Citation}

Shaik AR, Sripathi Rao BH, Husain A, D'Sa JL. Association Between Musculoskeletal Symptoms Experienced By Dentists and Selected Socio Demgraphic Variables in a Southern Karnataka District.Kathmandu Univ Med J 2012;38(2):9-13.

\begin{abstract}
Background

The majority of working dentists experience some type of musculoskeletal discomfort during the course of their professional career. The prevalence and location of musculoskeletal symptoms are influenced by work habits, postures adopted by dentists while performing their professional work and socio demographic variables.
\end{abstract}

\section{Objectives}

The current study was carried out to find the association between musculoskeletal symptoms experienced by dentists and selected socio demographic variables in a southern Karnataka district.

\section{Methods}

For this study 300 dentists were selected by using convenience sampling method among post graduate dental students, faculty members and private practitioners with more than one year of experience from in and around Mangalore city. In order to find the association, a pre-tested, self-administered questionnaire - Musculoskeletal Disorder Rating Scale was used

\section{Results}

The study showed that there was statistically significant association between frequency of pain and average patient(s) treated per day. The association between intensity of pain and average patient(s) treated per day was highly significant. Further there was a significant association between intensity of pain and field of dental practice. With regard to the field of dental practice, frequency of stiffness was significantly associated with the age. The association between frequency of stiffness and no. of year(s) in profession was highly significant.

\section{Conclusion}

The study revealed a significant association between musculoskeletal symptoms experienced by the dentists and socio demographic variables like; age, field of dental practice, no. of years in profession and average patients treated per day.

\section{KEYWORDS}

Dentists, musculoskeletal symptoms

\section{INTRODUCTION}

Musculoskeletal symptoms (MSS) are defined as pain and stiffness commonly experienced by dentists in the course of their professional career. The musculoskeletal health of dentists has been a subject of concern and has been studied by the researchers world over. The pain experienced by the dentists has been the main focus of attention. The studies have shown that dentists have a high frequency of musculoskeletal symptoms. ${ }^{1-3}$ The research has shown that being seated or standing made little difference on the frequency of pain experienced by the dentists rather 
affected the pattern of pain distribution among the body part. $^{4}$

Work-related musculoskeletal symptoms are of multifactorial in origin. ${ }^{5}$ Awareness on the MSS experienced by dentists has increased noticeably in recent years. Thus during the past several decades great deal of ergonomics and new technology has been integrated into the modern dental office like sit-down dentistry and fourhanded dentistry to provide better working conditions / environment to the dentists. ${ }^{6}$

The availability of highly sophisticated dental equipments, the scope for improving the occupational health of dental practitioners has expanded. But in spite of this development, dental practitioners still continue to experience chronic pain and stiffness in the back, neck and shoulders as occupational hazards, often leading to early retirement from the profession. ${ }^{7,8}$ Some investigations have shown that the prevalence and location of pain and other symptoms may be influenced by posture and work habits, as well as other demographic factors. Part-time Thai dentists were found to have a higher proportion of musculoskeletal problems than their full-time counterparts. Further the number of years since graduation was negatively correlated with musculoskeletal pain in the Thai dentists. ${ }^{9,10}$ The survey among different dental specialists showed that the Oral Surgeons have higher incidence of pain in the wrist than the rest of the dental professionals. ${ }^{11}$

The objective of the study was to find the association between musculoskeletal symptoms experienced by dentists and selected socio demographic variables in a Southern Karnataka district.

\section{METHODS}

There are four dental colleges and eighty private clinics in Mangalore city out of which two dental colleges (260 dentists) and twenty private clinics (40 dentists) were selected using convenience sampling method for the study. Dentists who were present during the data collection period and who fulfilled the sampling criteria were selected for the study. The study was conducted on 300 practicing dentists having work experience of more than one year. They were basically post graduate dental students, faculty members of dental colleges and private practitioners in and around Mangalore city.

In order to find the association between musculoskeletal symptoms (pain and stiffness) experienced by dentists and selected socio demographic variables a pre-tested, selfadministered questionnaire - Musculoskeletal Disorder Rating Scale (MDRS) was used. The MDRS consisted of Pain and Stiffness Scale and Socio Demographic Proforma.

The Pain and Stiffness Scale consisted of frequency of pain, frequency of stiffness, which have three components (always, sometimes and never) and intensity of pain which was assessed by 0-10 Numeric Pain Rating Scale (0: no pain 1-3: mild pain 4-6: moderate pain 7-10: severe pain). The Socio Demographic Proforma included questions related to age, gender, field of dental practice, and number of year in profession, average working hour per day, average work day per week, average patient treated per day, height and weight of the dentists.

The tool was developed by the researcher by validating with experts and reliability was established. Reliability for MDRS (pain and stiffness) was done by using Cronbach's alpha: frequency of pain - alpha $=0.79$; frequency of stiffness alpha $=0.73$; intensity of pain - alpha $=0.66$.

Ethical clearance to conduct the study was obtained from Yenepoya University Ethical Committee. After explaining the purpose of the study a written consent was obtained from the participants on voluntary basis and the questionnaire was handed over to the dentists to fill their responses.

Data were analysed using SPSS (Statistical Package for Social Sciences) version 17.0 software. The analysis was performed by using Chi-square $(\chi 2)$ test and statistical significance was accepted for $p<0.05$.

\section{RESULTS}

Majority $(82.7 \%)$ of the dentists were in the age group of 20-35 years. With regard to the no. of year(s) in profession, $49 \%$ were having one to five years of experience and $64 \%$ of them had average patient(s) treated per day between one to five. $14.7 \%$ were practicing conservative dentistry and $3 \%$ were practicing community dentistry.

Chi-square was computed to find the association between frequency and intensity of pain and selected socio demographic variables; that are age, no. of year(s) in profession, average patient(s) treated per day and field of dental practice are presented in table 1 and 2 . A significant association ( $\chi 2=8.88, p=0.031$ ) was found between frequency of pain and average patient(s) treated per day. The association between intensity of pain and average patient(s) treated per day was highly significant $(\chi 2=39.08$, $\mathrm{p}=0.001)$.

Frequency of pain (sometimes) and intensity of pain (mild) were more in conservative dentistry that is $31.8 \%$ and $88.6 \%$ respectively. Frequency of pain was independent of field of dental practice, However there was a significant association ( $\chi 2=29.10, p=0.047$ ) between intensity of pain and field of dental practice.

The association between frequency of stiffness and age, no. of year(s) in profession, average patient(s) treated per day and field of dental practice are presented in table 3 and 4. The frequency of stiffness was significantly associated with the age $(\chi 2=8.58, p=0.014)$ and the association between frequency of stiffness and no. of year(s) in profession was highly significant $(\chi 2=13.91, p=0.003)$. Chi-square computed showed that frequency of stiffness 
Table 1. Association between frequency and intensity of pain and age, no.of year(s) in profession and average patient(s) treated per day.

\begin{tabular}{|c|c|c|c|c|c|c|c|c|}
\hline \multirow{2}{*}{ Variables } & \multirow{2}{*}{$N(\%)$} & \multicolumn{2}{|c|}{ Frequency of pain } & \multirow{2}{*}{$\begin{array}{l}\chi 2 \text { Value } \\
\text { ( } p \text { value) }\end{array}$} & \multicolumn{4}{|c|}{ Intensity of pain } \\
\hline & & Some times & never & & No pain & Mild pain & $\begin{array}{l}\text { Moderate } \\
\text { pain }\end{array}$ & $\begin{array}{l}\chi 2 \text { Value } \\
\text { ( } p \text { value) }\end{array}$ \\
\hline \multicolumn{9}{|c|}{ Age (years) } \\
\hline 20-35 & $248(82.7)$ & $47(19.0)$ & 201(81.0) & & $32(12.9)$ & $207(83.5)$ & 09(3.6) & \\
\hline $36-50$ & $38(12.7)$ & $07(18.4)$ & $31(81.6)$ & 0.06 & $02(5.3)$ & $34(89.5)$ & $2(5.3)$ & 2.59 \\
\hline $51-65$ & $14(4.6)$ & $03(21.4)$ & $11(78.6)$ & $(0.969) \ddagger$ & $02(14.3)$ & $12(85.7)$ & $0(0.0)$ & $0.629 \ddagger$ \\
\hline \multicolumn{9}{|c|}{ No. of year(s) in profession } \\
\hline $1-5$ & $147(49.0)$ & $25(17.0)$ & $122(83.0)$ & & $21(14.3)$ & $120(81.6)$ & $06(4.1)$ & \\
\hline $6-10$ & $115(38.3)$ & $22(19.1)$ & $93(80.9)$ & 1.77 & $14(12.2)$ & $98(85.2)$ & $03(2.6)$ & 6.57 \\
\hline 11-15 & $24(8.0)$ & $06(25.0)$ & $18(75.0)$ & $(0.62) \neq$ & $0(0.0)$ & 22(91.7) & $02(8.3)$ & $0.363 \ddagger$ \\
\hline $16-25$ & $14(4.7)$ & $04(28.6)$ & $10(71.4)$ & & $01(7.1)$ & 13(92.9) & $0(0.0)$ & \\
\hline \multicolumn{9}{|c|}{ Average patient(s) treated per day } \\
\hline $1-5$ & $192(64.0)$ & $31(16.1)$ & $161(83.9)$ & & $26(13.5)$ & $164(85.4)$ & $02(1.0)$ & \\
\hline $6-10$ & $68(22.6)$ & 13(19.1) & $55(80.9)$ & 8.88 & $06(8.8)$ & $61(89.7)$ & $01(1.50)$ & 39.08 \\
\hline $11-15$ & $25(8.3)$ & $06(24.0)$ & 19(76.0) & $(0.031)+$ & $03(12.0)$ & $18(72.0)$ & $04(16.0)$ & $0.001^{*}$ \\
\hline$\geq 16$ & $15(5.0)$ & $07(46.7)$ & $08(53.3)$ & & $01(6.7)$ & 10(66.7) & $04(26.7)$ & \\
\hline
\end{tabular}

*Statistically high significant $(p=0.001)$, † statistically significant $(p=0.031)$, ₹ statistically not significant $(p=0.969,0.62,0.629,0.363)$

Table 2. Association between frequency and intensity of pain and field of dental practice.

\begin{tabular}{|c|c|c|c|c|c|c|c|c|}
\hline \multirow{2}{*}{ Variables } & \multirow{2}{*}{$N(\%)$} & \multicolumn{2}{|c|}{ Frequency of pain } & \multirow{2}{*}{$\begin{array}{l}\chi 2 \text { value } \\
\text { ( } p \text { value) }\end{array}$} & \multicolumn{3}{|c|}{ Intensity of pain } & \multirow{2}{*}{$\begin{array}{l}\chi 2 \text { value } \\
\text { ( } p \text { value }\end{array}$} \\
\hline & & Some times & never & & $\begin{array}{l}\text { No } \\
\text { pain }\end{array}$ & $\begin{array}{l}\text { Mild } \\
\text { pain }\end{array}$ & $\begin{array}{l}\text { Moderate } \\
\text { pain }\end{array}$ & \\
\hline \multicolumn{9}{|l|}{ Field of dental practice } \\
\hline Oral Medicine & $26(8.7)$ & $03(11.5)$ & $23(88.5)$ & & $03(11.5)$ & $22(84.6)$ & $01(3.8)$ & \\
\hline Oral Surgery & $18(6.0)$ & $07(38.9)$ & $11(61.1)$ & & $0(0.0)$ & $18(100)$ & $0(0.0)$ & \\
\hline Pedodontics & $25(8.3)$ & $07(28.0)$ & $18(72.0)$ & & $0(0.0)$ & $23(92.0)$ & $02(8.0)$ & \\
\hline Orthodontics & $42(14.0)$ & 07(16.7) & $35(83.3)$ & 16.05 & $06(14.3)$ & $36(85.7)$ & $0(0.0)$ & 29.10 \\
\hline Prosthodontics & $41(13.7)$ & $04(9.8)$ & $37(90.2)$ & $0.066 \ddagger$ & $07(17.1)$ & $32(78.0)$ & $02(4.9)$ & $0.047+$ \\
\hline Periodontics & $34(11.3)$ & $06(17.6)$ & $28(82.4)$ & & $04(11.8)$ & $30(88.2)$ & $0(0.0)$ & \\
\hline Conservative dentistry & $44(14.7)$ & $14(31.8)$ & $30(68.2)$ & & $02(4.5)$ & $39(88.6)$ & $03(6.8)$ & \\
\hline Community dentistry & $09(3.0)$ & $01(11.1)$ & $08(88.9)$ & & $03(33.3)$ & $06(66.7)$ & $0(0.0)$ & \\
\hline Oral Pathology & $21(7.0)$ & $02(9.5)$ & 19(90.5) & & $07(33.3)$ & 13(61.9) & $01(4.8)$ & \\
\hline General practice & $40(13.3)$ & $06(15.0)$ & $34(85.0)$ & & $04(10.0)$ & $34(85.0)$ & $02(5.0)$ & \\
\hline
\end{tabular}

† Statistically significant $(p=0.047)$, ‡ statistically not significant $(p=0.066)$

was independent of average patient(s) treated per day and field of dental practice.

However the study showed that the gender, average working hour(s) per day, average work day(s) per week, height and weight of the dentists had no significant association with the frequency and intensity of pain and frequency of stiffness.

\section{DISCUSSION}

The mechanism of musculoskeletal symptoms production has been studied extensively. The onset of modern dentistry, as evidenced by four handed dentistry, has made the major part of the dentists' tasks purely sedentary in nature which has resulted in dramatic rise in musculoskeletal symptoms. ${ }^{12}$

While there are studies that claim that the frequency of pain and stiffness remains stable with age. ${ }^{13}$ Some researchers believe that musculoskeletal discomfort is maximum around the sixth decade of life. ${ }^{14}$ Shaik et al 
Table 3. Association between frequency of stiffness and age, no. of year(s) in profession and average patient(s) treated per day.

$\begin{array}{lll}\text { Variables } N(\%) & \text { Frequency of pain } & \begin{array}{l}\chi 2 \text { Value } \\ \text { ( } p \text { value) }\end{array} \\ & \begin{array}{l}\text { Some value } \\ \text { times }\end{array} & \\ & & \end{array}$

\begin{tabular}{|llllll|}
\hline Age (years) & & & & & \\
$20-35$ & $248(82.7)$ & $15(6.0)$ & $233(94.0)$ & & \\
\hline $36-50$ & $38(12.7)$ & $07(18.4)$ & $31(81.6)$ & 8.58 & $0.014+$ \\
\hline $51-65$ & $14(4.6)$ & $0(0.0)$ & $14(100.0)$ & & \\
\hline
\end{tabular}

No. of year(s) in profession

\begin{tabular}{llllll|}
\hline $1-5$ & $\begin{array}{l}147 \\
(49.0)\end{array}$ & $05(3.4)$ & $142(96.6)$ & & \\
\hline $6-10$ & $\begin{array}{l}115 \\
(38.3)\end{array}$ & $09(7.8)$ & $106(92.2)$ & 13.91 & $0.003^{*}$ \\
& $24(8.0)$ & $05(20.8)$ & $19(79.2)$ & & \\
$11-15$ & $14(4.7)$ & $03(21.4)$ & $11(78.6)$ & & \\
\hline $16-25$ & $14)$ &
\end{tabular}

Average patient(s) treated per day

$\begin{array}{llllll}1-5 & 192 & 12(6.3) & 180(93.8) & & \\ & (64.0) & & & & \\ 6-10 & 68(22.6) & 05(7.5) & 62(92.5) & 3.58 & 0.465 \ddagger \\ 11-15 & 25(8.3) & 04(16.0) & 21(84.0) & & \\ \geq 16 & 15(5.0) & 01(10.0) & 14(93.3) & & \end{array}$

$15(5.0) \quad 01(10.0) \quad 14(93.3)$

* Statistically highly significant $(\mathrm{p}=0.003)$, † statistically significant $(p=0.014))$, ₹ statistically not significant $(p=0.465)$

Table 4. Association between frequency of stiffness and field of dental practice.

\begin{tabular}{|c|c|c|c|c|c|}
\hline \multirow{2}{*}{ Variables } & \multirow{2}{*}{$N(\%)$} & \multicolumn{2}{|c|}{ Frequency of pain } & \multirow[b]{2}{*}{$\begin{array}{l}x^{2} \\
\text { value }\end{array}$} & \multirow[b]{2}{*}{ pvalue } \\
\hline & & $\begin{array}{l}\text { Some } \\
\text { times }\end{array}$ & never & & \\
\hline \multicolumn{6}{|c|}{ Field of dental practice } \\
\hline Oral Medicine & $26(8.7)$ & $01(3.8)$ & $25(96.2)$ & & \\
\hline Oral Surgery & $18(6.0)$ & $04(22.2)$ & $14(77.8)$ & & \\
\hline Pedodontics & $25(8.3)$ & $02(8.0)$ & $23(92.0)$ & & \\
\hline Orthodontics & $42(14.0)$ & $01(2.4)$ & 41 (97.6) & 12.18 & $0.203 \neq$ \\
\hline Prosthodontics & $41(13.7)$ & $02(4.9)$ & 39 (95.1) & & \\
\hline Periodontics & $34(11.3)$ & $03(8.8)$ & 31 (91.2) & & \\
\hline $\begin{array}{l}\text { Conservative } \\
\text { dentistry }\end{array}$ & $44(14.7)$ & 05 (11.4) & 39 (88.6) & & \\
\hline $\begin{array}{l}\text { Community } \\
\text { dentistry }\end{array}$ & $09(3.0)$ & $0(0.0)$ & 09 (100) & & \\
\hline Oral Pathology & $21(7.0)$ & $0(0.0)$ & $21(100)$ & & \\
\hline General practice & $40(13.3)$ & $04(10.0)$ & $36(90.0)$ & & \\
\hline
\end{tabular}

found that there was a statistically significant association between the age and the frequency of stiffness in the neck $(p=0.030)$, hip/thigh $(p=0.031) .15$ Coinciding with these studies, the current study found that there was statistically significant association ( $\chi 2=8.58, p=0.014$ ) between the frequency of stiffness and age.

Further, we found that there was a statistically significant association between number of patients treated per day by the dentists with frequency of pain in the hip/thigh $(p=0.024)$ and wrist $(p=0.048) .{ }^{15}$ In case of intensity of pain there was a statistically significant association with the patients treated per day and the pain experienced in the back $(p=0.018)$. Coinciding with this study, the current study showed that a significant association $(\chi 2=8.88, p=0.031)$ between frequency of pain and average patient(s) treated per day and the association between intensity of pain and average patient(s) treated per day was highly significant $(x 2=39.08, p=0.001)$. Further the association between frequency of stiffness and no. of year(s) in profession was highly significant $(\chi 2=13.91, p=0.003)$.

Studies have shown that age has significant impact on number of hours worked per week by the dentists. Male dentists having age more than 55 years had more impact than the female dentists in terms of hours worked. ${ }^{16}$ For men, the findings again were consistent with those of other studies showing that male dentists reduce the number of hours they work per week after the age of 55 years, with further reduction in hours after the age of 65 years. The current study showed that there was no significant association between musculoskeletal symptoms experienced by the dentists and average working hour(s) per day and average work day(s) per week.

Yamalik, reported that age, gender and perceived general health status are strongly associated with chronic complaints and seeking medical care. ${ }^{17}$ Elderly people, women and those who experience poor general health, also report more chronic complaints. Back pain has been reported to be more associated with absenteeism from work than neck and shoulder pain.

Lalumandir et.al reported that all dental specialties show a high occurrence of musculoskeletal symptoms but with variations in frequency and locations. ${ }^{18}$ They found prevalence of hand/wrist complaints in orthodontists while differences in prevalence of complaints between general dentists and specialists have been reported for many body sites.

Rundcrantz et al. found musculoskeletal discomfort to be more frequent in the oral surgeons than in other dental specialists, and attributed this to an increased workload. ${ }^{19}$ The current study found that frequency of pain (sometimes) and intensity of pain (mild) were maximum in Conservative dentistry that is $31.8 \%$ and $88.6 \%$ respectively. The association between field of dental practice and intensity of pain was statistically significant $(\chi 2=29.10, p=0.047)$.

\section{CONCLUSION}

Musculoskeletal symptoms are significant occupational health problem in dentists. This study revealed that the musculoskeletal symptoms experienced by the dentists were significantly associated with the various socio demographic variables like age, field of dental practice, no. of years in profession and average patients treated per 
day by the dentists. We recommend that, between the treatment sessions mini breaks should be taken and chair side directional stretching exercises and proper positioning of the patient and the dentist should be adopted to minimize the musculoskeletal symptoms among dentists.

\section{ACKNOWLEDGEMENT}

The authors are thankful to all the dentists who participated in the study. Special thanks to Dr. Ghulam Jeelani Qadiri, MD, Dean, Faculty of Medicine, Dr. T.M. Sivaswamy,MD, Senior Prof. Dept. of Community Medicne, Mr. Shashidhar Kotian, Msc, Statistician and Dr. Arun A.B., PhD, Dy.Director, Yenepoya Research Center.

\section{REFERENCES}

1. Shugars D, Miller D, Williams D, Fishburne C, Srickland D. Musculoskeletal pain among general dentists. General Dentistry $1987 ; 4: 272-6$.

2. Murtomaa H. Work related complaints of dentists and dental assistants. Int Arch Occup Environ Health 1982;50:231-6.

3. Kajland A, Lindvall T, Nilsson T. Occupational medical aspects of the dental profession. Work Environ Health 1974;11:100-7.

4. Benny V, Keith $\vee$ Mechanisms leading to musculoskeletal disorders in dentistry. J Am Dent Assoc 2003;134:1344-50.

5. Westgaard RH Effects of physical and mental stressors on muscle pain. Scand J Work Environ Health 1999; 25(Supplement):19 - 24.

6. Finkbeiner BL. Four-handed dentistry revisited. J Contemp Dent Pract 2000;1(4):74-86.

7. Miller DJ, Shugars DA, The health of the dental professional. J Am Dent Assoc 1987; 114:515-8.

8. Burke FJ, Main JR, Freeman R, The practice of dentistry: an assessment of reasons for premature retirement. British Dent J 1997;182(7):2504.

9. Chowanadisai S, Kukiattrakoon B, Yapong B, Kedjarune U, Leggat PA. Occupational health problems of dentists in southern Thailand. Int Dent J 2000;50(1): 36-40.

10. Åkesson I, Johnsson B, Rylander L, Moritz U, Skerfving S. Musculoskeletal disorders among female dental personnel: clinical examination and a 5-year follow-up study of symptoms. Int Arch Occup Environ Health 1999;72(6):395-403.
11. Harutunian K, Gargallo-Albiol J, Figueiredo R, Gay-Escoda C. Ergonomics and musculoskeletal pain among postgraduatestudents and faculty members of the School of Dentistry of the University of Barcelona (Spain). A cross-sectional study. Med Oral Patol Oral Cir Bucal 2011;16:425-9.

12. Pope M (1993) Muybridge lecture. In: proceedings of XIVth Congress International Society of Biomechanics, Paris.

13. Lehto TU, Helenius HY, Alaranto HT Musculoskeletal symptoms of dentists assessed by a multi disciplinary approach. Community Dent Oral Epidemiol 1991;19: 38-44.

14. Ratzon NZ, Yaros T, Mizlik A, Kanner T. Musculoskeletal symptoms among dentists in relation to work posture. Work 2000;15:153-158.

15. Shaik AR, Sripathi Rao BH, Husain A, D'Sa J. Work-related musculoskeletal disorders among dental surgeons: A pilot study. Contemp Clin Dent 2011;2:308-12.

16. American Dental Association. 1999 survey of career patterns: A comparison of dentists by gender and age group. Chicago: American Dental Association;2001.

17. 1Yamalik, N. Musculoskeletal disorders (MSDs) and dental practice Part 2. Risk factors for dentistry, magnitude of the problem, prevention, and dental ergonomics. Int Dent J 2007; 57:45-54.

18. Lalumandier JA, McPheeSD, Parrott CB, Vendemia M. Muscu-loskeletal pain: prevalence, prevention, and differences among den $\neg$ tal office personnel. Gen Dent 2001; 49:160-6.

19. Rundcrantz BL, Johnsson B, Moritz U. Cervical pain and discomfort among dentists. Epidemiological, clinical and therapeutic aspects. Part 1. A survey of pain and discomfort. Swed Dent J 1990;14:71-80. 